\section{Author's response: allergic rhinitis and asthma require an integrated management}

I thank Drs Camargos and colleagues for their comments ${ }^{1}$ regarding our paper. $^{2}$ I agree with our Brazilian colleagues that additional randomised controlled trials are needed assessing the effect of allergic rhinitis treatment on asthma control in children.

In the study by Camargos et al, steroid naive asthmatic patients received fluticasone propionate either through a face mask, while breathing through their nose with their mouth closed, or through a spacer with a mouthpiece for oral inhalation. The latter group also received $0.9 \%$ sodium chloride intranasal spray. ${ }^{3}$ Although asthma clinical score, forced expiratory volume in 1's, allergic rhinitis symptom score and nasal inspiratory peak flow improved in both groups from baseline, no statistically significant difference was found between the two treatment groups, except for rhinitis symptom score and nasal inspiratory peakflow at 8 weeks in favour of the experimental group $(p<0.001$ and $p=0.008)$. Because all patients were steroid naive, treatment with inhaled corticosteroids could be expected to produce improvements in both groups. I agree with Camargos and coworkers that the larger improvement of the rhinitis symptom score and the nasal inspiratory peak flow in the experimental group confirm that concomitant treatment of allergic rhinitis in asthmatic children is important. In the other article examining simultaneous treatment of asthma and allergic rhinitis in children with asthma using inhaled corticosteroids, there was also no statistically significant difference between the two treatment arms. ${ }^{4}$

In the studies by Camargos et al and our study, ${ }^{3} 4$ improvement of asthma control was noted when treating allergic rhinitis. To confirm these observations, a rigorously designed randomised controlled trial examining the effects of nasal corticosteroid therapy for allergic rhinitis on asthma control should be performed.

\section{Eric de Groot}

Correspondence to Eric de Groot, Pediatrics, Isala klinieken, Dokter van Heesweg 2, Zwolle 8025 AB, The Netherlands; e.p.de.groot@isala.nl

Competing interests None.

Provenance and peer review Commissioned; internally peer reviewed.

Accepted 2 February 2012

Published Online First 1 March 2012

Thorax 2012;67:1014.

doi:10.1136/thoraxjnl-2012-201703

\section{REFERENCES}

1. Camargos $\mathbf{P}$, Ibiapina C, Lasmar L, et al. Allergic rhinitis and asthma require an integrated management. Thorax 2012. doi:10.1136/thoraxjnl-2012-201666

2. de Groot EP, Nijkamp A, Duiverman EJ, et al. Allergic rhinitis is associated with poor asthma control in children with asthma. Thorax 2012;67:582-7.

3. Camargos P, Ibiapina C, Lasmar L, et al. Obtaining concomitant control of allergic rhinitis and asthma with a nasally inhaled corticosteroid. Allergy 2007;62:310-16.

4. Camargos $\mathbf{P}$, Rodrigues ME, Lasmar LM. Simultaneous treatment of asthma and allergic rhinitis. Ped Pulmonol 2004;38:186-92. 